\title{
A survey of the pain experienced by males and females with Fabry disease
}

\author{
Andrea L Gibas MA ${ }^{1}$, Regan Klatt MS CCGC CGC ${ }^{2}$, Jack Johnson BFA ${ }^{3}$, Joe TR Clarke MD PhD FRCPC ${ }^{2}$, Joel Katz PhD J,4 $^{1,4}$
}

\begin{abstract}
AL Gibas, R Klatt, J Johnson, JTR Clarke, J Katz. A survey of the pain experienced by males and females with Fabry disease. Pain Res Manage 2006;11(3):185-192.
\end{abstract}

BACKGROUND: The clinical onset of Fabry disease, a rare, X-linked, multisystemic disorder, is marked by neuropathic pain. Males suffer extensively from this disease. Females, as genetic 'carriers', have traditionally been viewed as either asymptomatic or mildly afflicted with this disease.

OBJECTIVES: To describe Fabry-related pain and compare experiences between the sexes. Patients' perceptions of physician pain assessments were also examined.

METHODS: A disease-specific questionnaire was accessible on-line (www.fabry.org) and mailed to 552 members of a Fabry disease support group.

RESULTS: The response rate was $14.3 \%$ for the support group-based mail questionnaire. Females $(58.0 \%)$ were significantly older (mean \pm SD $45.9 \pm 13.5$ years) than males (mean \pm SD 40.0 \pm 12.1 ; $t[86]=-2.11, \mathrm{P}<0.05)$. Females were diagnosed with Fabry disease later $(31.1 \pm 14.0$ years $)$ than males $(24.2 \pm 11.9$ years; $t[86]=-2.43$, $\mathrm{P}<0.05$ ). Females (mean score for pain disability rating 3.0 \pm 1.4 ) suffered more extensive disability from migraine pain (mean score $2.2 \pm 1.3 ; \mathrm{F}[1,74]=45.0, \mathrm{P}<0.005)$, and, unlike males, did not exhibit a decline in pain intensity with disease duration. Satisfaction with physician pain assessments was moderate.

CONCLUSIONS: Contrary to the traditional view of females as carriers, females with Fabry disease experienced intense disease-related pain; pain produced comparable distress and impairment in both sexes. The diagnostic delay and absence of a decline in pain symptoms over time in females suggest additional disease burden. Females may be triply disadvantaged in the health care system due to disease rarity, devalued carrier status and sex.

Key Words: Acute and chronic pain; Descriptive analysis; Fabry disease; Lysosomal storage disorder; Male and female comparison; Pain and genetics

Cabry disease, also known as Anderson-Fabry disease or angiokeratoma corporis diffusum (1), is a rare, multisystemic lysosomal storage disorder (2). This disease is characterized by a deficiency of a lysosomal enzyme, $\alpha$-galactosidase $A$ (3-6), resulting in the gradual accumulation of its principal substrate, a glycolipid $(3-5,7)$. The suffering that Fabry disease imposes is severe (8); the excessive lipid storage causes progressive damage to multiple bodily systems including the eyes, kidneys, heart and brain $(4,9)$. As a consequence, the lives of affected males are significantly shortened, with death often occurring in the fourth or fifth decade due to renal failure, or cardiovascular or cerebrovascular disease (5-7).

\section{Une enquête sur la douleur ressentie par les hommes et les femmes atteints de la maladie de Fabry}

HISTORIQUE : L'apparition clinique de la maladie de Fabry, un trouble multisystémique rare lié au X, est marquée par des douleurs neuropathiques. Les hommes souffrent énormément de cette maladie. Les femmes, en qualité de porteuses génétiques, ont toujours été perçues comme asymptomatiques ou peu touchées par la maladie.

OBJECTIFS : Décrire les douleurs reliées à la maladie de Fabry et comparer les expériences selon le sexe. La perception qu'ont les patients des évaluations de la douleur par les médecins est également évaluée.

MÉTHODOLOGIE : Un questionnaire portant sur la maladie était accessible par voie électronique (www.fabry,org) et a été posté à 552 membres d'un groupe d'entraide de la maladie de Fabry.

RÉSULTATS : Le taux de réponse était de $14,3 \%$ au sein du groupe d'entraide ayant reçu le questionnaire par la poste. Les femmes $(58,0 \%)$

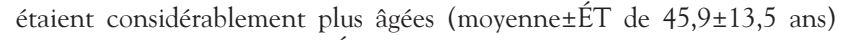
que les hommes (moyenne \pm ÉT de 40,0 $\pm 12,1$ ans; $t[86]=-2,11, \mathrm{P}<0,05$ ). Le diagnostic de maladie de Fabry était posé plus tard chez les femmes $(31,1 \pm 14,0$ ans $)$ que chez les hommes $(24,2 \pm 11,9$ ans; $t[86]=-2,43$, $\mathrm{P}<0,05)$. Les femmes (indice moyen d'appréciation de l'incapacité causée par la douleur de 3,0 $\pm 1,4$ ) souffraient d'une incapacité plus marquée causée par les douleurs migraineuses (indice moyen de 2,2 $\pm 1,3$, $\mathrm{F}[1,74]=45,0, \mathrm{P}<0,005)$ et, contrairement aux hommes, ne remarquaient pas de diminution de l'intensité de la douleur proportionnelle à la durée de la maladie. Les patients étaient modérément satisfaits de l'évaluation de la douleur par les médecins.

CONCLUSIONS : Contrairement au point de vue classique au sujet des femmes porteuses, les femmes atteintes de la maladie de Fabry souffrent d'intenses douleurs reliées à leur maladie, et la douleur provoquait des souffrances et une atteinte similaires chez les deux sexes. Le retard de diagnostic et l'absence de diminution des symptômes de la douleur chez les femmes au fil du temps laissent supposer un fardeau supplémentaire. Les femmes seraient peut-être triplement désavantagées au sein du système de santé en raison de leur sexe, de la rareté de la maladie et de la dévaluation de l'état du porteur.

\section{FEMALES AS FABRY DISEASE 'CARRIERS'} Although the exact population prevalence of this rare disease is unknown, estimates range from one in 40,000 to one in 117,000 (10). The rarity of the disease may be attributable to its sex-linked mode of transmission (3). Affected males transmit the genetic mutation only to female offspring, producing females heterozygous for Fabry disease (11). Literature regarding Fabry disease has traditionally recognized the heterozygous female as simply a vehicle for the transmission of the disease as a genetic 'carrier'. This has perpetuated a misconception that the majority of female Fabry disease patients are asymptomatic $(2,12)$, or endure intermittent and mild symptoms of the

${ }^{1}$ York University, Department of Psychology and School of Kinesiology and Health Science; ${ }^{2}$ Hospital for Sick Children, Division of Clinical E3 Metabolic Genetics, Toronto, Ontario; ${ }^{3}$ Executive Director, Fabry Support 8 Information Group, Concordia, Missouri, USA; ${ }^{4}$ Toronto General Hospital, Department of Anesthesia E Pain Management, Toronto, Ontario

Correspondence and reprints: Dr Joel Katz, Department of Psychology, York University, 4700 Keele Street, BSB 232, Toronto, Ontario

M3J 1P3. Telephone 416-736-2100 ext 40557, fax 416-736-5814, e-mail jkatz@yorku.ca 
disease (2,13). Allegedly, the 'full syndrome' is manifested in males only, and incompletely in female carriers (14). However, approximately $1 \%$ of female Fabry disease patients have been reported to have symptoms as severe as those of males (15).

Contrary to the traditional view of females as carriers (ie, asymptomatic or mildly symptomatic), a more recent position suggests that the onset of Fabry disease symptoms in females may be comparable with that of males, and that all carriers be closely examined because most may be symptomatic for Fabry disease (16). Recent studies indicate that between $60 \%$ and $70 \%$ of carrier females may express classic symptoms of the disease (3), and up to 30\% may manifest multiple serious symptoms of the disease (17). Although the progression to organ failure may be slower for females than for males (18), the normal lifespan for females with Fabry disease is shorter than that of nonaffected females in the general population. Heterozygous females live, on average, to 70 years of age, a reduction of between 10 and 15 years (19).

\section{NEUROPATHIC PAIN AND FABRY DISEASE}

The clinical onset of Fabry disease is striking and unique, marked by the occurrence of neuropathic pain. In fact, neuropathic pain in the hands and feet is the first symptom most commonly reported by Fabry disease patients $(16,20)$. Fabry disease pain has been reported as early as three years of age in males, and in females, as young as six years (16). In addition, significant visceral (ie, abdominal and gastrointestinal) and/or joint pain may also be experienced $(11,21,22)$.

Fabry disease patients experience varying degrees of pain, with infrequent periods of complete remission (23). Fabry disease pain typically occurs daily (13). Two nonmutually exclusive types of pain often co-occur in Fabry disease: chronic acroparesthesias defined as, "agonizing pain of burning, tingling character, often associated with a deep ache" (16, page 768); and episodic pain of a lancinating (or "shooting") quality, termed 'Fabry crises' $(16,21,24)$. The chronic acroparesthesias of Fabry disease are experienced as a low to moderate intensity, constant, burning pain, predominantly located in the palms of the hands and soles of the feet $(5,7)$. With time, the background pain may spread proximally (3).

Fabry crises are experienced as intermittent attacks of sharp, lancinating pain of variable duration $(25,26)$. The episodic crises may persist for minutes to weeks (8). As the neuropathy underlying the pain progresses (26), the pain of the Fabry crises may also escalate in severity (21). External factors may trigger a painful crisis (27). Painful crises are frequently accompanied by low-grade fever and an increase in limb and/or joint pain $(4,21)$. This episodic pain is very common, and is estimated to occur in $90 \%$ of males between five and 15 years of age who have been diagnosed with the classic phenotype of Fabry disease $(23,28)$. In a study of 26 hemizygous male Fabry disease patients, short-form McGill Pain Questionnaire (29) scores ranged between five and eight (of 45), suggestive of mild pain (9). In another study, the average score on the Brief Pain Inventory (30) for pain at its worst was $5.4 \pm 0.45$ on a scale of zero to 10 , suggestive of moderate pain (31).

FEMALE 'CARRIERS' AND FABRY DISEASE PAIN The prevalence and nature of the pain experienced by female carriers have been contested despite that, empirically, it has not been well documented. Compared with pain in males, pain has been reported to occur in only $10 \%$ of females, and when it occurs it is said to be intermittent $(12,13)$. The onset of the neuropathic pain is also reported to be later than in males (24,32).

In contrast, more recent data suggest that females develop neuropathic pain with the same characteristics and within the same age range as males (33). A high prevalence of neuropathic pain has been reported among heterozygous females in the first two decades of life (34). Seventy per cent of 60 heterozygous Fabry disease females reported neuropathic pain: 41 of 42 had pain attacks or crises, and 16 of 42 had continuous background pain (17). Mean background pain was rated as 6.8 on an 11-point scale. The intensity increased on average to 7.4 during a Fabry crisis, suggestive of moderate to severe pain (17). These more recent data suggest that neuropathic pain is a significant problem in women with Fabry disease, but information is lacking on the quality, intensity and frequency of the pain.

The primary objective of the present study was to examine the similarities and differences in the nature of the pain experienced by males and females with Fabry disease. A comparison of Fabry disease pain experiences between the sexes has not been formally conducted to date.

\section{PHYSICIAN ASSESSMENT AND MANAGEMENT OF FABRY DISEASE PAIN}

By virtue of Fabry disease's rarity, few medical professionals will ever have occasion to treat a person with Fabry disease. However, Fabry-related pain may be the "only clue" to the initial presentation of this rare disease (28); complaints of painful neuropathy are often how those affected with Fabry disease are first brought to medical attention. This suggests that earlier recognition by medical professionals of the distinctive pattern of Fabry disease pain may prove important in forestalling the subsequent progressive nature of the disease. In addition, both patients and clinicians have suggested that traditional, physicianderived pain assessments may not be accurate in capturing the distinctive experience of Fabry disease pain $(9,34)$. Therefore, a secondary objective of the present study was to examine how Fabry disease patients view physician-based pain assessments, and what improvements (if any) they might suggest. To our knowledge, Fabry disease patient perceptions of physician pain assessment and management have not been previously studied.

\section{Study questionnaire}

\section{METHODS}

Because a Fabry disease-specific survey does not exist, a brief questionnaire was developed by the authors to measure two separate constructs: Fabry disease symptomatology (including pain); and patient perceptions about physician assessments of Fabry disease pain. The questionnaire consisted of five-point Likert rating scales and yes/no questions focused on patient perceptions of Fabryrelated pain, including quantitative descriptors of the neuropathic pain (eg, intensity, frequency), and quality of life. Patient perceptions of physician assessments of Fabry disease pain were also included. The pain questions were derived, in part, from previously validated pain questionnaires, and/or questions that had been utilized in previous studies (35). Five-point numeric rating scales were used to assess Fabry disease pain intensity and pain unpleasantness. Numerical rating scales of this nature have been shown to be reliable and valid measures of neuropathic pain (35). Internal consistency of the Fabry disease questionnaire was high; 
Cronbach's alpha was 0.90 for the Fabry disease pain items and 0.91 for items measuring patient perceptions of physician assessments of Fabry disease pain. Two open-ended questions were included to gather qualitative data regarding the two constructs of interest. The qualitative data from these two questions are not the subject of this report.

\section{Study procedure}

The study was reviewed and approved by the Research Ethics Board at The Hospital for Sick Children, Toronto, Ontario, and the Human Participants Review Committee at York University, Toronto, Ontario. On April 28 and 30, and May 6 and 9, 2003, the questionnaire was made available electronically on the discussion page of a patient-run Fabry disease support group Web site (Fabry Support \& Information Group [FSIG]; www.fabry.org). To ensure that only Fabry disease patients completed the questionnaire, participants were required to print out the form, complete it by hand and mail it to the FSIG. A member of the FSIG (JJ) reviewed the questionnaires, stripped them of any identifying information and mailed the anonymous forms to the researchers.

To generate additional Fabry disease patient responses, a copy of the questionnaire was mailed to 552 members of the FSIG (221 males, 230 females and 101 sex not indicated). Of the 552 members, 454 identified themselves as Fabry disease patients, and 98 as family members or a nonspecified relationship. No exclusion criteria were specified for this study. The respondents resided primarily within the United States, although a minority was from Canada and Europe. The response rate increased with the use of this second, mail-based recruitment method. As with the on-line questionnaire, completed questionnaires were mailed back to the FSIG for review (ie, ensuring that duplicate on-line and mail surveys were not completed), stripped of any identifying information and mailed to the researchers for scoring and analysis.

\section{Data analysis}

Data were analyzed using the Statistical Package for the Social Sciences (SPSS for Windows, release 12.0, USA) and Primer of Biostatistics: The Program (version 4.0, McGraw Hill, USA) (36). Demographic and clinical variables and questionnaire scores were summarized using descriptive statistics. $\chi^{2}$ test for two-way tables was used to analyze categorical frequency data between males and females. For continuous variables, data from males and females were compared by two-tailed $t$ test for independent samples. Bonferroni's type I error rate correction (alpha/number of tests) for multiple tests of significance was applied. Pain ratings associated with the experience of everyday pains and the various qualities or dimensions of Fabry disease pain were analyzed by a two-way between-within ANOVA using sex as the betweensubjects factor and pain experience as the within-subjects factor.

\section{Characteristics of the sample}

\section{RESULTS}

Ninety-six completed questionnaires were returned. Seventeen questionnaires were returned from the FSIG Web site and 79 from the direct mailing. Due to the nature of the Web-based survey, a response rate could not be determined. The response rate from the mail survey sent to the $552 \mathrm{mem}$ bers of the FSIG support group was $14.3 \%$. Significant differences were not evident on key variables (eg, age at diagnosis, age, sex, pain intensity) compared between the mailed and on-line questionnaires. Of the 96 questionnaires, eight were excluded for the following reasons: one questionnaire was

\begin{tabular}{|c|c|c|c|c|c|c|}
\hline & \multicolumn{2}{|c|}{ Total } & \multicolumn{2}{|c|}{ Male } & \multicolumn{2}{|c|}{ Female } \\
\hline & Mean & SD & Mean & SD & Mean & SD \\
\hline \multicolumn{7}{|c|}{ NRS intensity } \\
\hline Least & 1.67 & 0.77 & 1.59 & 0.83 & 1.72 & 0.73 \\
\hline Average & 2.47 & 0.95 & 2.42 & 0.91 & 2.51 & 0.98 \\
\hline Worst & 4.11 & 1.00 & 4.43 & 0.84 & 3.88 & 1.11 \\
\hline \multicolumn{7}{|c|}{ NRS unpleasantness } \\
\hline Least & 1.85 & 0.90 & 1.84 & 0.90 & 1.86 & 0.91 \\
\hline Average & 2.60 & 0.98 & 2.49 & 0.96 & 2.68 & 1.00 \\
\hline Worst & 4.17 & 1.05 & 4.38 & 1.04 & 4.02 & 1.04 \\
\hline
\end{tabular}

negative for both Fabry disease and carrier status (\#21, female), and seven questionnaires reported not experiencing Fabry-related pain and were incomplete (six females, one male). Demographic data were not available to compare the responders with the nonresponders.

The remaining 88 participants comprised the sample for the present study and consisted of patients diagnosed with Fabry disease and currently symptomatic for disease-related pain. Participants were predominantly female $(n=51,58.0 \%)$. The response rate for this sample of Fabry disease patients mirrors the expected proportion of males and females afflicted with this disease in the general population. In addition, the proportion of males (0.4) and females (0.6) responding to the FSIG mailing did not differ significantly from the proportion of selfidentified males (0.49) and females (0.51) in the FSIG data base $\left(\chi^{2}[1]=1.69, \mathrm{P}=0.19\right)$. The mean age $\pm \mathrm{SD}$ of the participants was $43.4 \pm 13.2$ years, with females $(45.9 \pm 13.5$ years $)$ significantly older than males $(40.0 \pm 12.1$ years, $t[86]=-2.11$, $\mathrm{P}<0.05)$. Mean age $\pm \mathrm{SD}$ at diagnosis of Fabry disease was significantly later for females $(31.1 \pm 14.0$ years $)$ than for males $(24.2 \pm 11.9$ years, $t[86]=-2.43, \mathrm{P}<0.05)$.

\section{Fabry disease pain intensity}

The intensity of Fabry-related pain experienced at its 'least', 'average' and 'worst' was examined with a five-point numeric rating scale (Table 1). Transformation was applied to the worst and least data to normalize the data. A two-way ANOVA indicated a significant main effect of pain intensity $(\mathrm{F}[2,164]=744.2, \mathrm{P}<0.05)$. Fabry disease pain intensity differed significantly among the least, average and worst pain experiences. The intensity $\times$ sex interaction $(F[2,164]=1.33$, $\mathrm{P}>0.05)$ and main effect for sex $(\mathrm{F}[1,82]=0.03, \mathrm{P}>0.05)$ were not significant. Thus, there were no significant differences between males and females in least, average and worst experiences of Fabry disease pain intensity when type I error rate was adjusted for multiple comparisons using a Bonferroni correction. Age was significantly and negatively correlated with Fabry-related pain at its worst for males (Pearson's $r[37]=-0.33, \mathrm{P}<0.05$ ) but not for females (Pearson's $r[51]=-0.12, P>0.05$ ).

Pain unpleasantness and pain intensity were strongly positively correlated for least, average and worst pain, for both males and females.

Fabry-related pain was reported to be the most intense (mean \pm SD score $4.0 \pm 1.0$ ) when compared with five common pain 


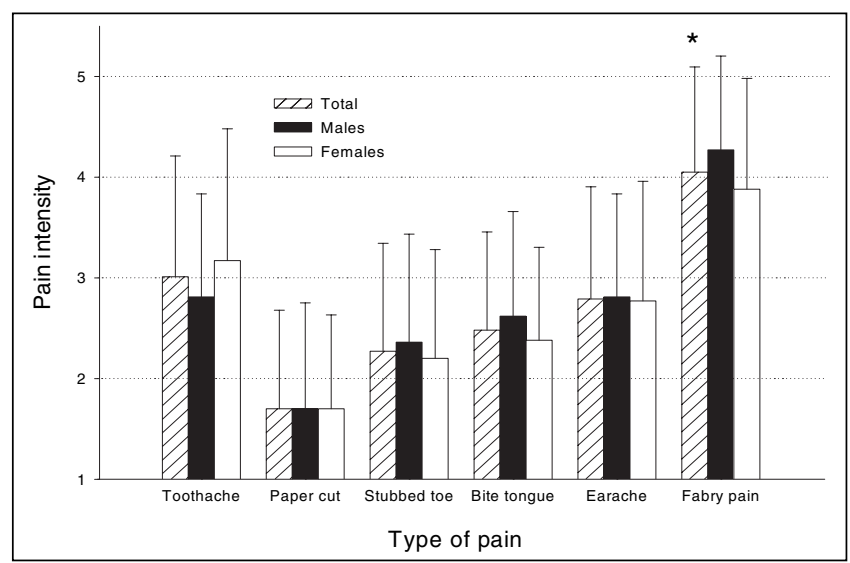

Figure 1) Pain intensity ratings of various everyday pains compared with ratings of Fabry disease-related pain $(1=$ not at all intense to $5=$ as intense as can be). Fabry disease-related pain was rated significantly more intense than each of the other pains, for both males and females for multiple comparisons of Fabry disease-related pain with each of the other five pains using Bonferroni's type I error rate correction. $* P<0.005$

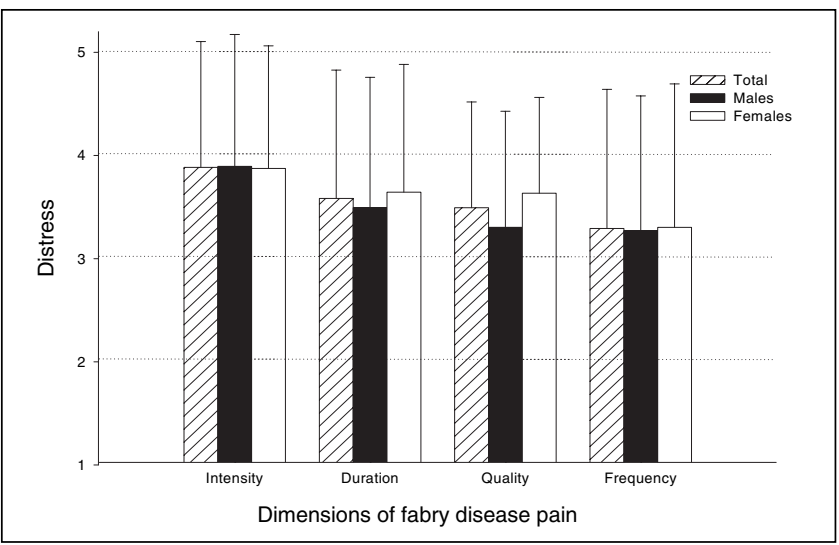

Figure 2) Ratings of how distressing the different dimensions of Fabry disease-related pain were reported to be by females and males ( 1 = least distressing to $5=$ most distressing). There were no significant differences in the ratings between females and males

experiences (Figure 1). Two-way ANOVA revealed a significant main effect for type of pain $(\mathrm{F}[5,390]=67.77, \mathrm{P}<0.01)$. The main effect for sex $(F[1,78]=0.44, P>0.05)$, and the sex $\times$ type of pain interaction $(\mathrm{F}[5,390]=1.43, \mathrm{P}>0.05)$ were not significant. Bonferroni-corrected multiple pair-wise comparisons showed that Fabry pain intensity was rated significantly higher than the other five common pain experiences: toothache $(t[83]=-5.88, \mathrm{P}<0.01)$, stubbed toe $(t[83]=-10.90, \mathrm{P}<0.01)$, paper cut $(t[85]=-16.49, \mathrm{P}<0.01)$, earache $(t[83]=7.75$, $\mathrm{P}<0.01)$ and biting of tongue $(t[85]=11.17, \mathrm{P}<0.01)$.

Figure 2 depicts distress ratings for four principal dimensions of Fabry-related pain: intensity, duration, quality and frequency. The two-way ANOVA revealed a significant main effect for the four dimensions of Fabry-related pain (F [3, $252]=6.39, \mathrm{P}<0.001)$. The main effect for sex $(\mathrm{F}[1,84]=0.33$, $\mathrm{P}>0.05)$, and the sex $\times$ pain dimension interaction $(\mathrm{F}[3$, $252]=0.69, \mathrm{P}>0.05$ ) were not significant. Bonferroni-adjusted pair-wise comparisons showed that distress levels were significantly greater for Fabry-related pain intensity (mean $\pm \mathrm{SD}$

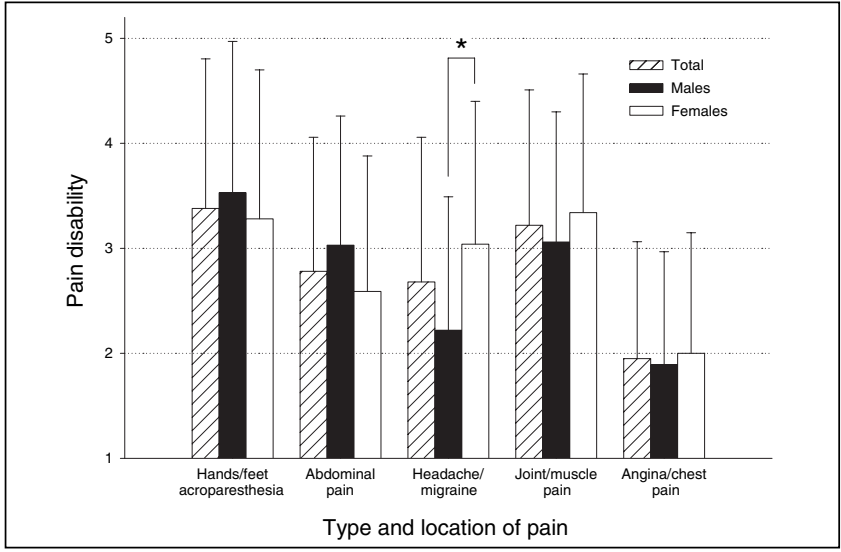

Figure 3) Ratings of how disabling the various types of Fabry diseaserelated pain were reported to be $(1=$ least disabling to $5=$ most disabling). Simple effects of sex by type of pain interaction showed that female ratings of headache and migraine disability were significantly greater than male ratings. $* \mathrm{P}<0.005$

score $3.9 \pm 1.2$ ) than for frequency (mean \pm SD score $3.3 \pm 1.3$; $t[86]=4.21, \mathrm{P}<0.001)$.

\section{Fabry disease pain disability}

Figure 3 shows the pain disability ratings by sex for the various types of Fabry disease-related pain. The two-way ANOVA on pain disability ratings revealed a significant main effect of type of Fabry-related pain (abdominal pain, headache/migraine pain, joint/muscle pain, angina/chest pain and hands/feet acroparesthesia; $\mathrm{F}[4,296]=24.93, \mathrm{P}<0.001)$, a nonsignificant main effect of sex $(F[1,74]=0.73, P>0.05)$ and a significant sex $\times$ type of pain interaction $(\mathrm{F}[4,296]=3.55, \mathrm{P}<0.05)$. Bonferroniadjusted simple effects of the interaction showed that the only significant difference in pain disability ratings between the sexes was for headache or migraine pain, which was greater for females (mean score 3.0 \pm 1.4 ) than males (mean \pm SD score $2.2 \pm 1.3 ; \mathrm{F}[1,74]=-45.00, \mathrm{P}<0.005)$.

\section{Quality of life and Fabry disease pain}

Disease-specific pain, rated over the previous six months, adversely affected the quality of life of the participants (mean \pm SD score 3.3 \pm 1.3 ). Quality of life was impacted to a similar extent for both male (mean \pm SD score $3.4 \pm 1.3$ ) and female Fabry disease patients (mean \pm SD score $3.2 \pm 1.3$ ). Further support for the interference of Fabry-related pain on quality of life was evident in response to the open-ended question, "What aspects of your life are most affected by Fabry-related pain?" Of the total responses $(n=88)$, disease-related pain was reported to interfere substantially in everyday life $(n=31,35.2 \%)$, family and social functions $(n=18,20.5 \%)$, employment $(n=19$, $21.6 \%)$, and leisure and physical activities $(n=33,37.5 \%)$.

\section{Associated medical problems}

Table 2 shows the self-reported prevalence of associated medical problems experienced in the past year by this sample. After correcting for multiple comparisons, there were no differences in the proportion of males and females reporting associated medical problems. Increasing age correlated significantly with greater disease burden (ie, more numerous symptoms) for 
TABLE 2

Self-reported prevalence in the past year of medical problems associated with Fabry disease shown for the total sample, male and female respondents

\begin{tabular}{|c|c|c|c|c|c|c|}
\hline & \multicolumn{2}{|c|}{ Total } & \multicolumn{2}{|c|}{ Male } & \multicolumn{2}{|c|}{ Female } \\
\hline & $\mathbf{n}$ & Yes (\%) & $\mathbf{n}$ & Yes (\%) & $\mathbf{n}$ & Yes $(\%)$ \\
\hline Kidney impairment or failure & 22 & 26.5 & 14 & 42.4 & 8 & 16.0 \\
\hline Stroke with lasting after effects & 3 & 3.8 & 3 & 8.8 & 0 & 0.0 \\
\hline $\begin{array}{l}\text { Transient ischemic attack } \\
\text { (small stroke) }\end{array}$ & 15 & 17.9 & 4 & 11.8 & 11 & 22.0 \\
\hline Vertigo (dizziness) & 69 & 79.3 & 27 & 75.0 & 42 & 82.4 \\
\hline Decreased sweating & 63 & 76.8 & 30 & 85.7 & 33 & 70.2 \\
\hline $\begin{array}{l}\text { Angiokeratomas (little } \\
\text { red/purple spots on the skin) }\end{array}$ & 71 & 81.6 & 34 & 91.9 & 37 & 74.0 \\
\hline Recurrent diarrhea & 62 & 72.1 & 32 & 88.9 & 30 & 60.0 \\
\hline Hearing loss & 50 & 57.5 & 24 & 66.7 & 26 & 51.0 \\
\hline Cataracts & 15 & 17.9 & 6 & 17.6 & 9 & 18.0 \\
\hline Chronic bronchitis & 20 & 24.1 & 7 & 21.2 & 13 & 26.0 \\
\hline Wheezing and/or asthma & 34 & 41.0 & 16 & 47.1 & 18 & 36.7 \\
\hline Shortness of breath & 59 & 68.6 & 22 & 59.5 & 37 & 75.5 \\
\hline Heart attack & 3 & 3.6 & 2 & 5.9 & 1 & 2.0 \\
\hline High blood pressure & 23 & 28.0 & 6 & 17.6 & 17 & 35.4 \\
\hline Heart palpitations & 47 & 56.6 & 18 & 51.4 & 29 & 60.4 \\
\hline Sexual dysfunction & 26 & 31.7 & 13 & 38.2 & 13 & 27.1 \\
\hline
\end{tabular}

males (Pearson's r [37] $=0.61, \mathrm{P}<0.001$ ) and females (Pearson's $\mathrm{r}[51]=0.35, \mathrm{P}<0.001)$. The difference between the two correlations was not significant (Fisher's $\mathrm{Z}$ transformation, $\mathrm{Z}=1.10$, $\mathrm{P}>0.05)$.

Physician assessment of patient Fabry disease pain

Global satisfaction with physician assessments of Fabry disease pain was moderate (mean \pm SD score 2.9 \pm 1.3 ). Male Fabry disease participants (mean \pm SD score $3.1 \pm 1.3$ ) were slightly, but not significantly, more satisfied by the assessment process than female participants (mean $\pm \mathrm{SD}$ score $2.8 \pm 1.2, t[83]=1.30$, $\mathrm{P}>0.05$ ). Table 3 shows that the main areas targeted by participants for improvement in physician-directed pain assessments included triggers of pain, measures that improve pain (medication, massage, etc) and the impact of pain on daily living. Female Fabry disease participants reported lower ratings than males on all but one of the elements of physician-derived pain assessments, but the differences were not statistically significant (all $\mathrm{P}>0.05)$.

Patient-rated physician understanding of Fabry-related pain was also perceived as moderate (mean \pm SD score $2.7 \pm 1.3$ ). Level of perceived physician understanding was comparable for males (mean \pm SD score 2.8 \pm 1.3 ) and females (mean \pm SD score $2.6 \pm 1.4 ; t[82]=0.61, \mathrm{P}>0.05)$.

\section{DISCUSSION}

Describing Fabry disease pain

The present pilot study is the first of its kind to explore the various facets of Fabry disease pain, and to document the similarities and differences in the experience of pain between the sexes. The most important finding resulting from the present study is that, with few exceptions, pain ratings by females were virtually indistinguishable from those of their male counterparts. Females and males with Fabry disease not only reported very similar pain intensity scores, but also comparable pain
TABLE 3

Patients rated how well their physicians assessed Fabry disease-related pain on a five-point scale*

\begin{tabular}{|c|c|c|c|c|c|c|}
\hline \multirow{2}{*}{$\begin{array}{l}\text { How well are the following } \\
\text { aspects of pain being } \\
\text { assessed by your doctor: }\end{array}$} & \multicolumn{2}{|c|}{ Total } & \multicolumn{2}{|c|}{ Male } & \multicolumn{2}{|c|}{ Female } \\
\hline & Mean & SD & Mean & SD & Mean & SD \\
\hline $\begin{array}{l}\text { Description of pain quality } \\
\text { (eg, burning, tingling, etc) }\end{array}$ & 2.94 & 1.31 & 3.00 & 1.18 & 2.89 & 1.42 \\
\hline Intensity of pain & 2.85 & 1.29 & 2.94 & 1.11 & 2.78 & 1.41 \\
\hline Duration of pain & 2.91 & 1.26 & 2.97 & 1.07 & 2.87 & 1.39 \\
\hline Frequency of pain & 2.93 & 1.26 & 3.06 & 1.14 & 2.82 & 1.35 \\
\hline Location of pain & 3.22 & 1.24 & 3.25 & 1.16 & 3.20 & 1.33 \\
\hline Triggers of pain & 2.58 & 1.28 & 2.60 & 1.17 & 2.57 & 1.37 \\
\hline $\begin{array}{l}\text { Measures that improve pain } \\
\text { (medication, massage, etc) }\end{array}$ & 2.90 & 1.40 & 2.86 & 1.31 & 2.93 & 1.48 \\
\hline Impact of pain on daily living & 2.64 & 1.26 & 2.75 & 1.20 & 2.55 & 1.30 \\
\hline
\end{tabular}

*1 = not well to 5 = very well

intensity and pain unpleasantness ratings for least, average and worst pain (Table 1). For both males and females, the intensity of Fabry-related pain stood out when compared with five other common pain experiences, and, for both sexes, Fabry disease pain was ranked as the most intense (Figure 1). The results of the present study also show that both male and female Fabry disease patients were moderately to highly distressed by all four dimensions of their disease-specific pain; namely, intensity, duration, frequency and quality (Figure 2). In addition, with the exception of migraine pain, males and females reported very similar levels of pain disability when rating other pains commonly experienced by patients with Fabry disease (Figure 3). The difference between the sexes for migraine pain disability is difficult to interpret because it is consistent with the greater incidence of migraine pain among females in the general population $(37,38)$ and, thus, may not be related to Fabry disease. Finally, quality of life was impaired to a similar extent for males and females. Taken together, these findings support the suggestion that pain ratings by females do not differ from those of males.

The results of the present study conflict with the way in which females with Fabry disease traditionally have been portrayed in the literature $(15,34)$. Most of the literature indicates that females experience symptoms of an attenuated form of the disease, with pain experiences minimized and/or regarded as less prevalent or intense compared with males $(15,23)$. Table 2 shows that associated symptoms of Fabry disease (eg, vertigo) were equally prevalent in both the male and female study sample. Females with Fabry disease have thus been typecast in the role of a genetic carrier, not as a disease sufferer or patient requiring symptom management. However, as discussed above, the results of the present study and other recent research $(17,39)$ suggest that the intensity of Fabry-related pain does not differ between male and female Fabry disease patients. This result has two possible implications: female Fabry disease patients experience pain equivalent in intensity to that of their male counterparts, as suggested in previous research $(9,17,26)$; or females may experience less intense pain, but are less likely to receive adequate pain management for their disease (40). This disparity in pain management may potentially be attributed to sex inequality; it has been consistently recognized that females are less likely to receive appropriate medical treatment for chronic diseases than males (41). The present study did not 
address this issue because we did not assess pain medication and pain management strategies. However, not only did males and females not differ significantly in terms of their ratings of Fabry disease pain intensity and pain unpleasantness (Table 1), but they also reported comparable levels of pain intensity in response to a variety of everyday events that typically give rise to pain (Figure 1).

Despite the overall similarities between males and females, significant sex differences were identified in the present study. First, males were diagnosed at a significantly earlier age than were females, with females also being older than males at age of first diagnosis. This finding is consistent with other studies showing that males generally are diagnosed in their 20s (7), and females in their 30s (18). The onset of Fabry disease symptoms (other than pain) may begin later in females than males $(24,42)$, whereas neuropathic pain appears to develop at a similar age among females and males (9).

Second, a decline in pain intensity correlated significantly with disease duration among males, but not females. A similar finding has been reported for males (11) but this relationship has not been examined previously among females. The negative correlation between pain and disease duration among males may indicate that, over time, progressive damage to small diameter $\mathrm{C}$ and $\mathrm{A}$-delta fibres may render them inactive, thereby gradually reducing the intensity of pain, or patients habituate to the daily, continuous pain of Fabry disease. In contrast, the absence of a significant relationship between pain and disease duration among females may be explained by a slower symptom progression in females and random $\mathrm{X}$ inactivation (ie, whereby one $\mathrm{X}$ chromosome in all cells becomes randomly inactivated during embryonic development $(17,43)$. Although MacDermot et al (17) did not examine the correlation between disease duration and pain intensity, they did report that $80 \%$ of their sample of 60 female Fabry disease patients (mean age 44.9 years) continued to experience pain. Further research is required to determine the relationship between disease duration and pain intensity among females with Fabry disease.

Taken together, the results of the present study suggest that, contrary to the traditional conception of females with Fabry disease, this sample of women suffered significantly from the symptoms of Fabry disease, as evidenced by diagnosis at a later age, indicating that they experienced a delay in receiving validation of their symptoms by medical health professionals and/or for receiving disease-specific treatment; experiencing the same intensity, interference and unpleasantness of Fabry disease as males; and no evidence of a lessening of pain symptoms over time.

\section{Physician assessment and management of Fabry disease pain}

Fabry disease patient satisfaction with physician pain assessments may be influenced by several factors. The approximate 10-year delay in receiving a diagnosis of Fabry disease, along with the large number of specialists seen $(3,4)$, may instill an inherent distrust (3) of health care professionals, and thus contribute to dissatisfaction with physician-derived assessments. Nevertheless, Fabry disease patients in this sample reported a moderate level of satisfaction with physician assessments of Fabry-related pain. Patients identified several areas that required improvement, including more thorough assessments of the triggers of pain, the modalities that improve pain (eg, medication, massage, etc), and the consequences of pain on daily living. Thus, these results have a practical application that may lead to more effective management of Fabry disease pain and greater pain relief to a suffering population.

A slightly greater number of females than males responded to the survey. The greater percentage of female (58\%) respondents than male for this sample of Fabry disease patients is consistent with the theoretical distribution of males and females afflicted with this disease in the general population. As well, the percentage of males and females who responded to the FSIG mailing did not differ significantly from the distribution of self-identified males and females in the FSIG database. The slightly greater number of female respondents is also consistent with finding that, in general, females are more likely than males to respond to questionnaires (44-46), or that females may have been more motivated than males to 'speak out' about pain experiences due to their encountering ignorance or neglect in health care settings. It is also possible that males may be inundated by solicitations for participation in research because they are typically the targeted population for examining Fabry disease and, therefore, were slightly less inclined to become involved. Regardless of the reasons, the proportion of males and females responding to the survey appears to accurately reflect the distribution of males and females afflicted with Fabry disease, both in the FSIG database and in the population at large.

\section{Study limitations}

One limitation of the present study is that not all items of our survey were validated. Specifically, the questions encompassing the additional medical symptoms of Fabry disease were developed by the authors without further validation (eg, by comparing patient responses with data obtained from medical records). Because of the nature of the survey method used to gather information, we were unable to obtain confirmation of patients' reports of symptoms and, therefore, we do not know the extent to which these reports reflect actual symptomatology. However, items regarding the pain scales administered were well validated and the survey as a whole had very good reliability.

A second limitation is that the participants in the present study may not be representative of the population of patients with Fabry disease. The very low response rate (approximately $14 \%$ ) introduces the possibility of a significant nonresponse bias because the vast majority of surveys were not returned. The reasons for the low response rate are not clear. Because the pool of potential participants is limited by the rarity of this disease, patients may be overly researched and feel overburdened and therefore less inclined to participate in a study without immediate, tangible benefits. As well, a sampling bias may exist because the participants were recruited from a Fabry disease support group. These individuals may exhibit a greater disease burden (ie, experience more pain than a typical Fabry disease patient) and/or may be more vocal with their pain experiences (47). Clinic recruitment was not a feasible option given the rarity of the disease (one in 40,000 to one in 117,000).

Another factor limiting the present results concerns the pain medication status of the participants. Because we did not obtain information about current pain treatment, we cannot comment on the extent to which the pain intensity 
and unpleasantness ratings were influenced by analgesic intake. However, the neuropathic pain associated with Fabry disease is intractable (26) and, studies suggest, only partially responsive to many of the available analgesic agents $(7,11,26,48,49)$.

\section{SUMMARY AND CONCLUSIONS}

The results of the present study are at odds with the conception of females as asymptomatic disease carriers and, instead, contribute to the growing body of research showing that females with Fabry disease report significant pain intensity, unpleasantness and disability. Female participants appeared to be burdened by Fabry disease, more so than traditionally conceptualized, because they were diagnosed at a later age, implying a delay in the receipt of potentially life-saving medical treatment; experienced the same intensity, interference and unpleasantness of Fabry disease as males; and did not exhibit a lessening of pain symptoms over time. Thus, female Fabry disease patients may be triply disadvantaged by the health care system because of disease rarity, devalued carrier

\section{REFERENCES}

1. Gomes I, Nora DB, Becker J, et al. Nerve conduction studies, electromyography and sympathetic skin response in Fabry's disease. J Neurol Sci 2003;214:21-5.

2. Doi Y, Toda G, Yano K. Sisters with atypical Fabry's disease with complete atrioventricular block. Heart 2003;89:e2.

3. Bennett RL, Hart KA, O'Rourke E, et al. Fabry disease in genetic counseling practice: Recommendations of the National Society of Genetic Counselors. J Genet Counsel 2002;11:121-46.

4. Brady RO, Grabowski GA, Thadhani R. Fabry disease: Review and new perspective. SynerMed Communications 2001;1:1-8.

5. Breunig F, Weidemann F, Beer M, et al. Fabry disease: Diagnosis and treatment. Kidney Int Suppl 2003;84:S181-5.

6. Grabowski GA, Hopkin RJ. Enzyme therapy for lysosomal storage disease: Principles, practice, and prospects. Annu Rev Genomics Hum Genet 2003;4:403-36.

7. Desnick RJ, Brady R, Barranger J, et al. Fabry disease, an underrecognized multisystemic disorder: Expert recommendations for diagnosis, management, and enzyme replacement therapy. Ann Intern Med 2003;138:338-46.

8. Stryker VL, Kreps C. Fabry disease. Am J Nurs 2001;101:39-44.

9. Schiffmann R, Kopp JB, Austin HA III, et al. Enzyme replacement therapy in Fabry disease: A randomized controlled trial. JAMA 2001;285:2743-9.

10. Meikle PJ, Hopwood JJ, Clague AE, Carey WF. Prevalence of lysosomal storage disorders. JAMA 1999;281:249-54.

11. Galanos J, Nicholls K, Grigg L, Kiers L, Crawford A, Becker G. Clinical features of Fabry's disease in Australian patients. Intern Med J 2002;32:575-84.

12. Chowdhury MM, Holt PJ. Pain in Anderson-Fabry's disease. Lancet 2001;357:887.

13. Ro LS, Chen ST, Tang LM, Hsu WC, Chang HS, Huang CC. Current perception threshold testing in Fabry's disease. Muscle Nerve 1999;22:1531-7.

14. Ohnishi A, Tateishi J, Matsumoto T, Shida K, Kuroiwa Y. Fabry disease: Cellular expression of enzyme deficiency in nerve xenografts. Neurology 1979;29:899-901.

15. Baehner F, Kampmann C, Whybra C, Miebach E, Wiethoff CM, Beck M. Enzyme replacement therapy in heterozygous females with Fabry disease: Results of a phase IIIB study. J Inherit Metab Dis 2003;26:617-27.

16. Ries M, Ramaswami U, Parini R, et al. The early clinical phenotype of Fabry disease: A study on 35 European children and adolescents. Eur J Pediatr 2003;162:767-72.

17. MacDermot KD, Holmes A, Miners AH. Anderson-Fabry disease: Clinical manifestations and impact of disease in a cohort of 60 obligate carrier females. J Med Genet 2001;38:769-75.

18. Mehta A, Ricci R, Widmer U, et al. Fabry disease defined: Baseline clinical manifestations of 366 patients in the Fabry Outcome Survey. Eur J Clin Invest 2004;34:236-42. status and sex. Given the methodological limitations and potential sampling bias in the present study, further research is required to evaluate the extent to which this conclusion applies to the general population of female Fabry disease patients.

ACKNOWLEDGEMENTS: The authors thank the members of the Fabry Support \& Information Group that participated in this research and Tom Buis for his help with statistical analysis. This paper is derived, in part, from the first author's Master's thesis.

FUNDING: Funds to conduct this research were provided by a grant from Transkaryotic Therapies, Inc, awarded to Dr Joe TR Clarke. Andrea Gibas was supported in part by a Fellowship from the Canadian Institutes of Health Research (CIHR) Strategic Training Program Grant, Pain: Molecules to Community and a CIHR Canada Graduate Scholarships Master's Award. Joel Katz is supported by a Canada Research Chair in Health Psychology at York University.
19. Pastores GM, Lien YH. Biochemical and molecular genetic basis of Fabry disease. J Am Soc Nephrol 2002;13(Suppl 2):S130-3.

20. Ries M, Gupta S, Moore DF, et al. Pediatric Fabry disease. Pediatrics 2005;115:e344-55.

21. Luciano CA, Russell JW, Banerjee TK, et al. Physiological characterization of neuropathy in Fabry's disease. Muscle Nerve 2002;26:622-9.

22. Pareyson D. Diagnosis of hereditary neuropathies in adult patients. J Neurol 2003;250:148-60.

23. Kahn P. Anderson-Fabry disease: A histopathological study of three cases with observations on the mechanism of production of pain. J Neurol Neurosurg Psychiatry 1973;36:1053-62.

24. Hilz MJ, Stemper B, Kolodny EH. Lower limb cold exposure induces pain and prolonged small fiber dysfunction in Fabry patients. Pain 2000;84:361-5.

25. Fukuhara N, Suzuki M, Fujita N, Tsubaki T. Fabry's disease on the mechanism of the peripheral nerve involvement. Acta Neuropathol (Berl) 1975;33:9-21.

26. MacDermot J, MacDermot KD. Neuropathic pain in AndersonFabry disease: Pathology and therapeutic options. Eur J Pharmacol 2001;429:121-5.

27. Beck M, Ries R. Fabry Disease: Clinical Manifestations, Diagnosis, and Therapy. Oxford: OCC Europe Ltd, for TKT Europe, 2001.

28. Chowdhury MM, Holt PJ. Burning fingers, but where is the fire? Br J Dermatol 2001;144:1286.

29. Melzack R. The short-form McGill Pain Questionnaire. Pain 1987;30:191-7

30. Cleeland CS, Ryan KM. Pain assessment: Global use of the Brief Pain Inventory. Ann Acad Med Singapore 1994;23:129-38.

31. Eng CM, Banikazemi M, Gordon RE, et al. A phase $1 / 2$ clinical trial of enzyme replacement in Fabry disease: Pharmacokinetic, substrate clearance, and safety studies. Am J Hum Genet 2001;68:711-22.

32. Hauser AC, Lorenz M, Sunder-Plassmann G. The expanding clinical spectrum of Anderson-Fabry disease: A challenge to diagnosis in the novel era of enzyme replacement therapy. J Intern Med 2004;255:629-36.

33. Schiffmann R, Scott LJ. Pathophysiology and assessment of neuropathic pain in Fabry disease. Acta Paediatr Suppl 2002;91:48-52.

34. Hopkin RJ, Bissler J, Grabowski GA. Comparative evaluation of alpha-galactosidase A infusions for treatment of Fabry disease. Genet Med 2003;5:144-53.

35. Turk DC, Melzack R, eds. Handbook of Pain Assessment. New York: Guilford Press, 1992.

36. Glantz SA. Primer of Biostatistics: The Program. New York: McGraw-Hill, 1997.

37. O'Brien B, Goeree R, Streiner D. Prevalence of migraine headache in 
Canada: A population-based survey. Int J Epidemiol 1994;23:1020-6. 38. Gilmour H, Wilkins K. Migraine. Health Rep 2001;12:23-40.

39. Whybra C, Kampmann C, Willers I, et al. Anderson-Fabry disease: Clinical manifestations of disease in female heterozygotes. J Inherit Metab Dis 2001;24:715-24.

40. Pinn VW. Sex and gender factors in medical studies: Implications for health and clinical practice. JAMA 2003;289:397-400.

41. Redman BK. Patient education services as oppressor? Health Care Women Int 2002;23:773-80.

42. Brady R. Fabry disease. In: Thomas P, Ochoa J, Berthold C, Carlstedt T, Corneliuson O, eds. Peripheral Neuropathy. Philadelphia: WB Saunders, 1993:1169-78.

42. Thurberg BL, Rennke H, Colvin RB, et al. Globotriaosylceramide accumulation in the Fabry kidney is cleared from multiple cell types after enzyme replacement therapy. Kidney Int 2002;62:1933-46.

44. Wild TC, Cunningham J, Adlaf E. Nonresponse in a follow-up to a representative telephone survey of adult drinkers. J Stud Alcohol 2001;62:257-61.

45. Dengler R, Roberts H, Rushton L. Lifestyle surveys - the complete answer? J Epidemiol Community Health 1997;51:46-51.

46. Picavet HS. National health surveys by mail or home interview: Effects on response. J Epidemiol Community Health 2001;55:408-13.

47. Gold KF, Pastores GM, Botteman MF, et al. Quality of life of patients with Fabry disease. Qual Life Res 2002;11:317-27.

48. Germain DP. Fabry disease: Recent advances in enzyme replacement therapy. Expert Opin Investig Drugs 2002;11:1467-76.

49. Gordon KE, Ludman MD, Finley GA. Successful treatment of painful crises of Fabry disease with low dose morphine. Pediatr Neurol 1995;12:250-1. 


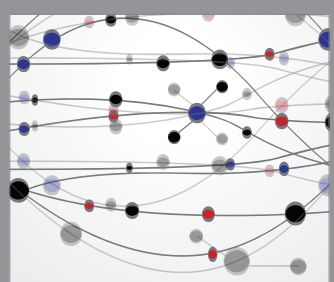

The Scientific World Journal
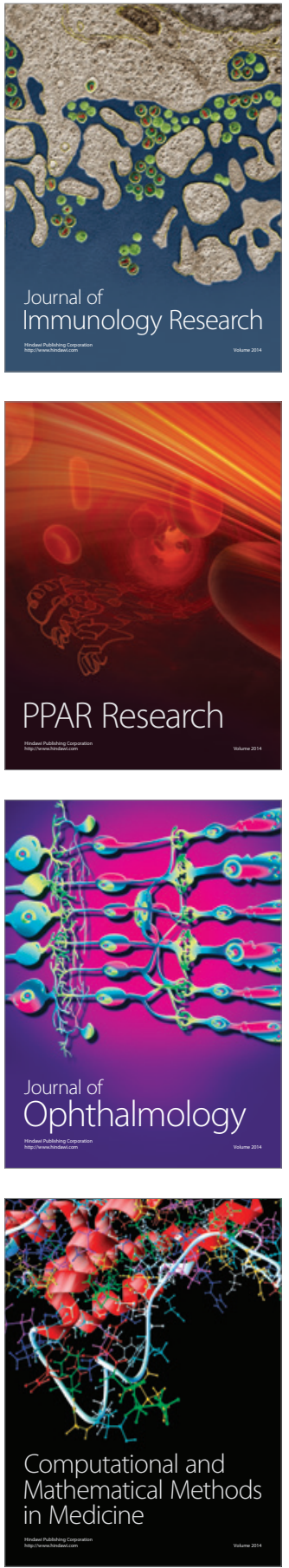

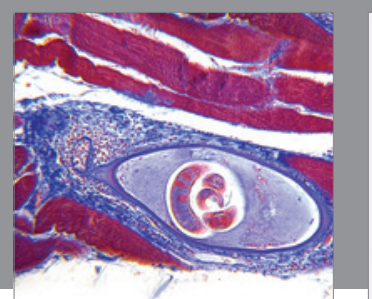

Gastroenterology Research and Practice



\section{Hindawi}

Submit your manuscripts at

http://www.hindawi.com
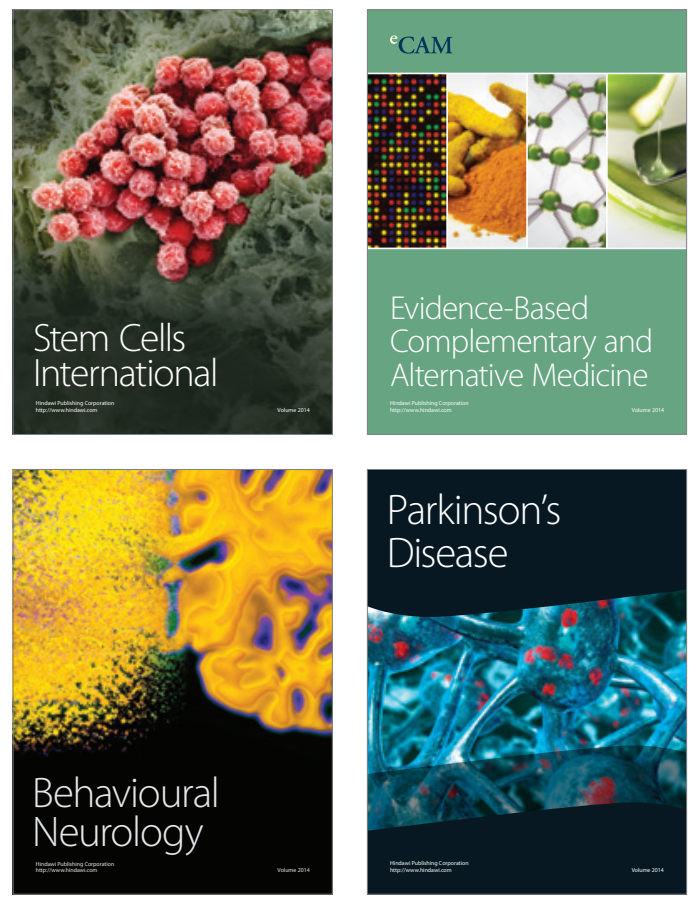
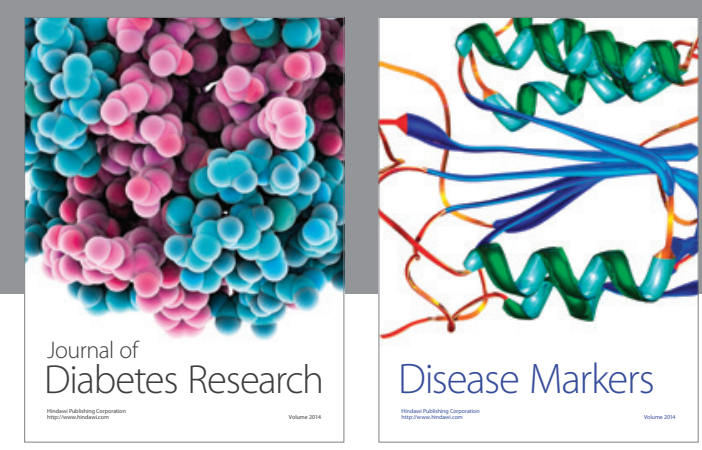

Disease Markers
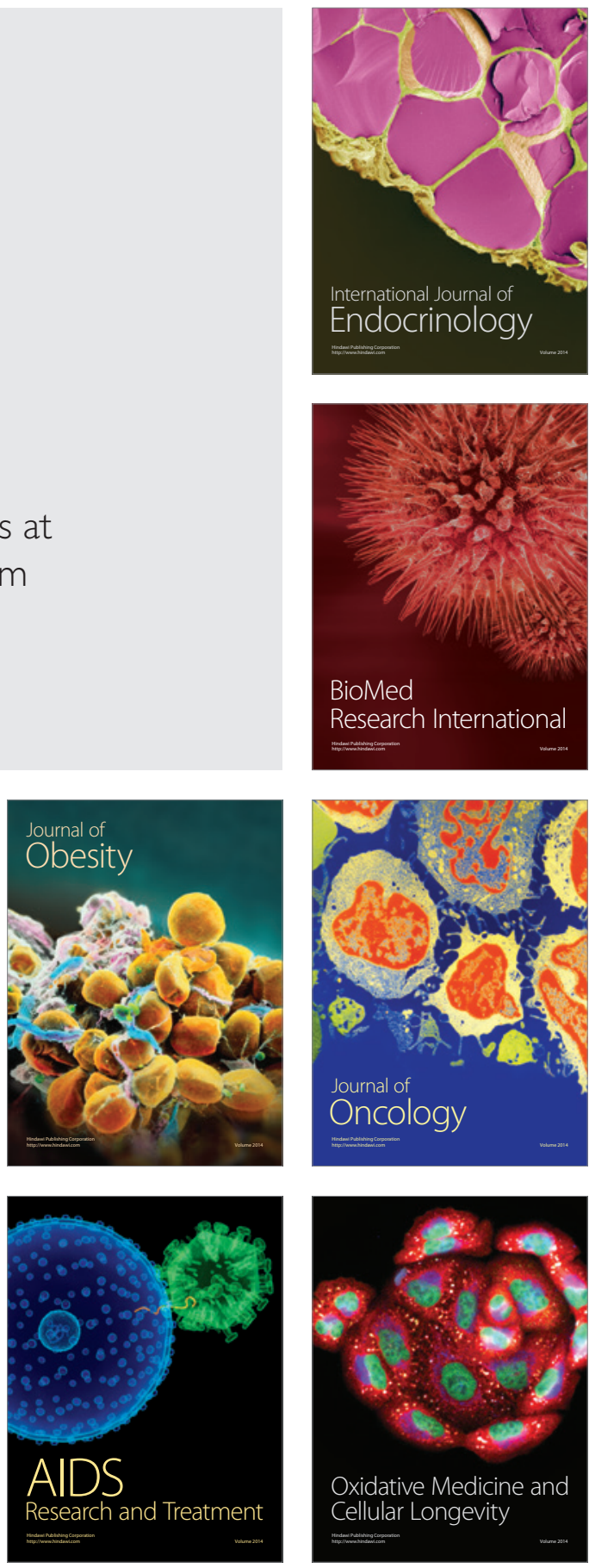